\title{
MOTIVOS DE EVASÃO E RETORNO DE JOVENS E ADULTOS AO ENSINO MÉDIO EM ALEGRE-ES
}

\author{
Annie da Silva Cassamali ${ }^{1}$ \\ Angélica Tomazeli da Silva ${ }^{2}$ \\ Anderson Lopes Peçanha ${ }^{3}$ \\ Afrânio Aguiar de Oliveira ${ }^{4}$
}

Resumo: O objetivo deste trabalho foi averiguar os principais problemas enfrentados por jovens e adultos, motivando-os a deixar a escola e quais os motivos que os fizeram retornar a mesma. A pesquisa foi realizada com os alunos de $1^{\circ}, 2^{\circ}$ e $3^{\circ}$ etapas da EJA (Educação de Jovens e Adultos), do ensino médio noturno, de uma escola pública estadual, localizada no município de Alegre, no Espírito Santo. Foi aplicado aos alunos um questionário composto por dez questões objetivas, além de informações como turma, idade e sexo, sem identificação do entrevistado. Participaram no total 70 alunos das três etapas da EJA. A idade mínima e máxima encontrada nesta modalidade de ensino foram 18 e 56 anos, respectivamente. Pode -se perceber que a maior causa de evasão escolar foi a necessidade de trabalhar para auxiliar na renda familiar, enquanto que o principal motivo de retorno escolar é conseguir um bom emprego. Dos entrevistados, 63 estudantes afirmaram que pretendem continuar os estudos após o ensino médio.

Palavras-chave: EJA; Educação; Questionário.

\footnotetext{
${ }^{1}$ Ciências Biológicas/Universidade Federal do Espírito Santo, Brasil. E-mail: anniecassamali@hotmail.com.

2 Ciências Biológicas/Universidade Federal do Espírito Santo, Brasil. E-mail: angelicatomazeli.bio.2012@gmail.com.

${ }^{3}$ Departamento de Biologia/ Universidade Federal do Espírito Santo, Brasil. E-mail: lopes.pecanha@gmail.com.

${ }^{4}$ Escola Estadual de Ensino Fundamental e Médio Aristeu Aguiar, Brasil. E-mail: afranioaguiar@bol.com.br.
} 